Editorial

\title{
A Great Specialty Deserves Recognition
}

\section{El merecido reconocimiento a una gran especialidad}

\author{
Joaquim Casañas Sintes ${ }^{1}$ \\ ${ }^{1}$ Chairman, Sociedad Española de Cirugía de Mano (SECMA) \\ Rev Iberam Cir Mano 2020;48:71.
}

We are currently living through truly unimaginable timed, and it is easy to fall into discouragement and apathy. However, as I like to say, "night will end and the sun will rise", and those who do not prepare and adapt to this situation will not be ready for a new day.

A lot can be said about the impact of the pandemic at both the national and global levels; there are profound changes in the way we work, our daily living, and professional perspectives.

Since the meeting of Sociedad Española de Cirugía de Mano (SECMA), we have been trying to remain firm in the goals set at the beginning of our term as Chairman and Board of Directors. Therefore, despite all difficulties, we want to start a highly exciting project that I believe will lead to optimism in this new sunrise.

We are thrilled to announce the institution of a National Training Plan in Hand Surgery including fundamental aspects required for a solid base in the training, knowledge and development of hand surgery both nationally and internationally.

Our Training Plan is based on models from the American Society for Surgery of the Hand (ASSH), the British Society for Surgery of the Hand (BSSH) and details from European societies that we have tried to adapt to the Spanish reality. Personally, for years I have been meeting with those in charge of education in the ASSH and BSSH to develop a project of substantial quality and excellence with our current board. Our program has been presented to Sociedad Española de Cirugía Ortopédica y Traumatología (SECOT) and to the
Federation of European Societies for Surgery of the Hand (FESSH), and it arose great admiration and respect, since it was considered an innovative model and an example for other European societies.

With all required rigor, demands and enthusiasm, we present the National Training Plan in Hand Surgery designed by SECMA, including a comprehensive training in eight educational blocks developed within 16 months. In addition, five to seven mentors per block will conduct a theoretical program based on readings, direct tutorials, and discussion of clinical cases for practical understanding. At the same time, there will be practical rotations in more than 50 teaching centers accredited by SECMA. This will lead to a complete, comprehensive training, which will enable the candidates to present themselves successfully both for the Spanish Diploma in Hand Surgery (Diploma Español en Cirugía de la Mano, DECIM) and the European Diploma in Hand Surgery (of the FESSH).

We hope that this first edition will be satisfactory for the candidates, mentors, and educational centers, leading to a long-lasting program. This is a true turning point in training and accreditation in Hand Surgery; may it be a beacon illuminating our work and our country as an example of excellence both nationally and internationally.

We are indeed optimistic that this training program will make us emerge stronger as a specialty and a profession. When the sun rises again, we will be on an excellent platform to reaffirm ourselves in our great specialty, Hand Surgery.
Address for correspondence Joaquim Casañas Sintes, Sociedad Española de Cirugía de Mano DOI https://doi.org/ (SECMA) (e-mail:kimcasanas@gmail.com). 10.1055/s-0040-1721008. ISSN 1698-8396.
Copyright $\odot 2020$ Thieme Revinter Publicações Ltda, Rio de Janeiro, Brazil 